\title{
Obstructive Sleep Apnea and the Risk of Cognitive Decline in Older Adults
}

\author{
Nadia Gosselin ${ }^{1,2,3}$, Andrée-Ann Baril ${ }^{1,2,3}$, Ricardo S. Osorio ${ }^{4,5}$, Marta Kaminska ${ }^{3,6}$, and Julie Carrier ${ }^{1,2,3}$ \\ ${ }^{1}$ Center for Advanced Research in Sleep Medicine, Hôpital du Sacré-Cœur de Montréal, Montreal, Canada; ${ }^{2}$ Université de Montréal, \\ Montreal, Canada; ${ }^{3}$ Canadian Sleep and Circadian Network, Canada; ${ }^{4}$ Center for Brain Health, New York University Langone Medical \\ Center, Manhattan, New York; ${ }^{5}$ Nathan S. Kline Institute for Psychiatric Research, Orangeburg, New York; and ${ }^{6}$ Respiratory \\ Epidemiology and Clinical Research Unit, Respiratory Division and Sleep Laboratory, Department of Medicine, McGill University Health \\ Center, Montreal, Canada
}

Insufficient or poor-quality sleep affects the immune system, weight management, glucose metabolism, cardiovascular and cerebrovascular health, cognition, work productivity, psychological well-being, and public safety. Recent findings indicate that sleep participates in the production and clearance of brain metabolic products (1) including those involved in dementia pathogenesis (2). How these new discoveries from animal models provide information on the impact of sleep disorders on brain health is a significant question.

The harmful effect of disturbed sleep on brain health is particularly important for older adults presenting obstructive sleep apnea (OSA). OSA causes not only sleep fragmentation but also intermittent hypoxia, which may affect both brain structure and function. OSA is common, particularly after the age of 65 years, when it has an estimated prevalence of at least $20 \%$ (3). Despite the increasing awareness of OSA and its consequences, one recent study showed that only $8 \%$ of older adults at high risk of OSA are tested with home or inlaboratory sleep studies; when at risk adults were investigated, OSA was confirmed in $94 \%$ of the cases (4). When OSA is diagnosed in older adults, clinicians face a dilemma as to whether patients with the most common forms of mild to moderate OSA and/or those without daytime sleepiness or comorbid health problems should be treated or not. Even when treatment is recommended, $30 \%$ of adults will refuse it (5) and more than $33 \%$ will not use it in the long term (6). These statistics suggest that many individuals who could benefit from treatment to possibly prevent neurodegeneration remain untreated. To improve treatment decision making and to increase adherence, we need to clearly depict the impact of OSA and its treatment on the aging brain. This Pulmonary Perspective presents the most recent findings on the neurocognitive consequences of OSA in older adults, a research field that has shown major growth in the past few years.

\section{Epidemiological Evidence Linking OSA to Cognitive Decline}

Recent meta-reviews have confirmed that OSA in middle-aged adults is associated with deficits in multiple cognitive domains. Attention, vigilance, episodic memory, working memory, and executive function are the cognitive domains most commonly impaired, whereas psychomotor abilities, language, and visuospatial function remain less systematically affected $(7,8)$. Studies show, however, an important heterogeneity in results due to differences in OSA definitions (e.g., self-reported vs. objectively confirmed OSA, apnea-hypopnea index cutoffs, differences in hypopnea criteria), neuropsychological tests (screening tests vs. comprehensive assessments), and variables adjusted for in statistical analyses (e.g., age, sex, APOE4 [apolipoprotein $\varepsilon 4$ allele], body mass index, years of education, cardiovascular disease, or depression).

In the older population, the link between OSA and risk of cognitive decline or dementia has only recently been documented in prospective cohorts. A study published in 2011 showed that among 298 women aged 82.3 years on average, a higher risk of developing mild cognitive impairment (MCI) or dementia at the 4.7year follow-up was associated with OSA, and linked to severity of hypoxia (9). More recently, a study performed with the Alzheimer's Disease Neuroimaging Initiative cohort showed that OSA was associated with an earlier age of progression to MCI or Alzheimer's disease (AD) (10). However, a study using the PROOFSYNAPSE cohort showed only small longitudinal changes in selected cognitive functions (11). This weak link between OSA and cognitive impairment was also the conclusion drawn in one recent systematic review and meta-analysis (12). In another meta-analysis of six prospective studies that included 212,943 participants more than 40 years of age, the authors concluded that adults with OSA were $26 \%$ more likely to develop significant cognitive decline or dementia at the 3-to 15-year follow-up (8). With these new findings in mind, clinicians now face the challenge of correctly identifying patients at greater risk of cognitive decline, particularly in those without daytime symptoms in whom treatment is not systematically proposed.

(Received in original form January 31, 2018; accepted in final form August 15, 2018)

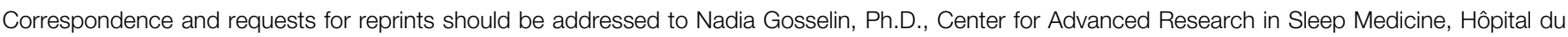
Sacré-Cœur de Montréal, 5400 boulevard Gouin Ouest, local J-5135, Montreal, QC, H4J 1C5 Canada. E-mail: nadia.gosselin@umontreal.ca.

Am J Respir Crit Care Med Vol 199, Iss 2, pp 142-148, Jan 15, 2019

Copyright (C) 2019 by the American Thoracic Society

Originally Published in Press as DOI: 10.1164/rccm.201801-0204PP on August 16, 2018

Internet address: www.atsjournals.org 


\section{Candidate Mechanisms That Could Link OSA to Cognitive Decline}

Why and how OSA is linked to dementia are questions that are generating intensive research efforts. Untreated OSA can make the brain more vulnerable to neurodegenerative processes by gradually altering its structure and functioning (13). Figure 1 presents candidate mechanisms that could explain the increased risk of abnormal cognitive decline in older adults with OSA. One potential mechanism relates to the crucial role of sleep in optimal cognitive functioning. In fact, studies consistently show that sleep continuity, slow-wave sleep (SWS), REM sleep, $\mathrm{K}$-complexes, and sleep spindles have specific and essential roles in neurogenesis (14), synaptic plasticity (15), and next-day vigilance (16), as well as in memory formation and consolidation $(17,18)$. OSA is associated with major and chronic changes in sleep characteristics, including sleep fragmentation, decrease in SWS and
REM sleep (19), and possible changes in sleep spindles (20) and K-complexes (21). Although hypothetical, these repetitive sleep architecture alterations may lead not only to next-day neurocognitive deficits, but also to changes in brain structure (e.g., alteration of white and gray matter, changes in cerebral networks) due to chronic impairment of sleep-dependent neurogenesis and synaptic plasticity. Consequently, when a neurodegenerative process occurs, the apneic brain could be more vulnerable to the clinical expression of dementia (22).

There are also recent studies that link OSA to AD biomarkers, namely $\mathrm{A} \beta 42$ and tau proteins, that accumulate in the form of plaques or tangles in the $\mathrm{AD}$ brain (23). In humans, a study performed in a sleep clinic reported lower cerebrospinal fluid (CSF) $\mathrm{A} \beta 42$ and higher total tau/A $\beta 42$ ratio levels in untreated individuals with OSA than in those with treated OSA and control subjects (24). In that study, patients with OSA treated with continuous positive airway pressure
(CPAP) had normal $A \beta 42$ and total tau/A $\beta 42$ ratio levels. These CSF findings suggest an accumulation of amyloid plaques and tau protein in the brain. A similar study performed in communitydwelling elderly adults confirmed these findings by showing that the severity of OSA was associated with 2-year longitudinal decreases in CSF A $\beta 42$ (25). Furthermore, in a recent study, neuronally derived proteins (CSF A $\beta 40, A \beta 42$, neurogranin, and VILIP-1 [visinin-like protein-1]) were lower in a group of 10 patients with OSA compared with 31 control subjects (26).

In terms of mechanism, hypoxia, sleep disruption, and impaired SWS in OSA could all be responsible for accentuation of $\mathrm{AD}$ biomarkers. Animal models and a few human studies support a link between $A \beta$ generation, production, and clearance in association with disturbed sleep and hypoxia. More specifically, recent studies suggest that sleep fragmentation and reduced SWS can increase $A \beta$ deposition (27). Interestingly, in a mouse model,

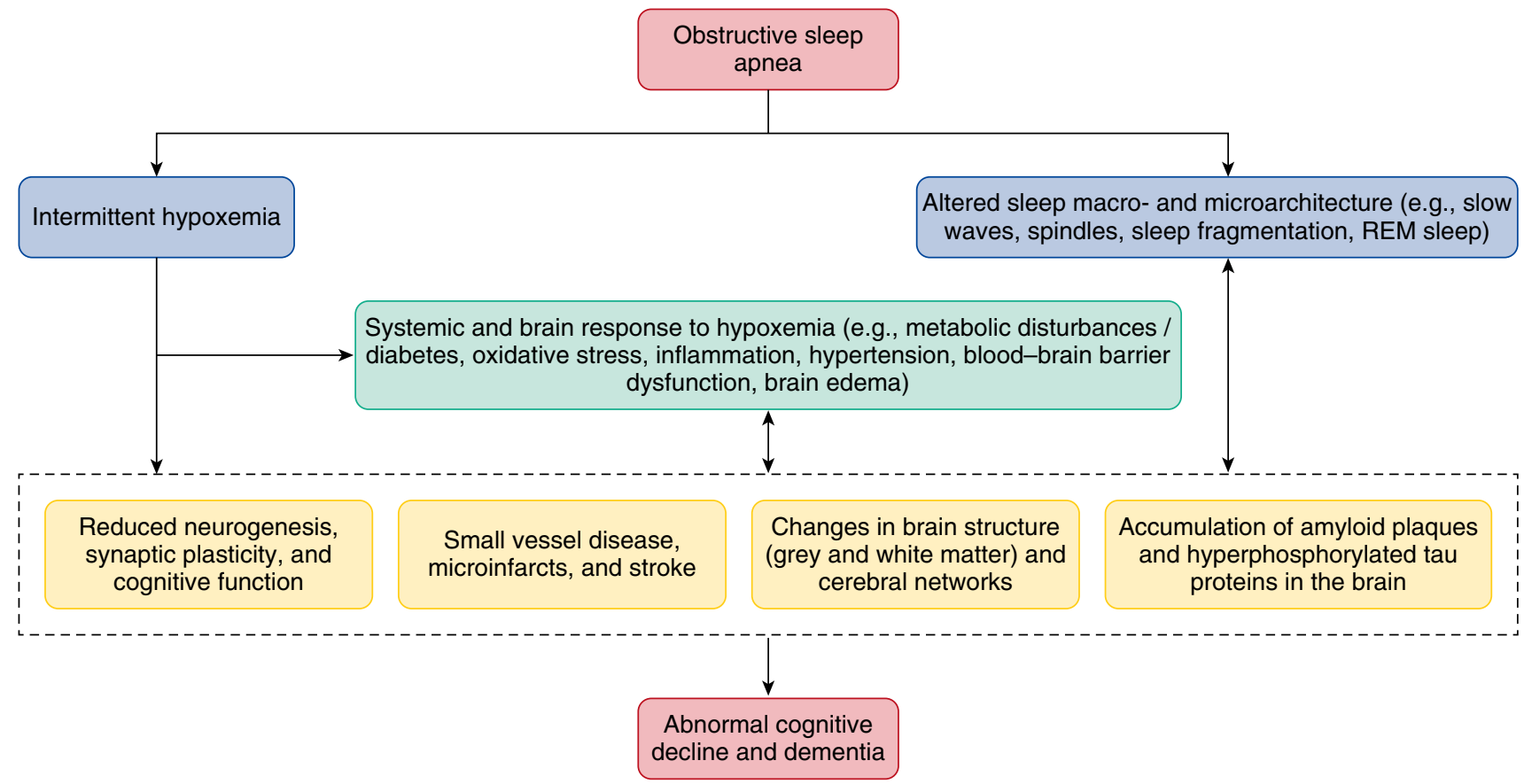

Figure 1. Schematic representation of possible mechanisms linking obstructive sleep apnea to dementia. Obstructive sleep apnea leads to intermittent hypoxemia and changes in sleep macro- and microarchitecture. Intermittent hypoxemia probably causes systemic and brain responses that include metabolic disturbances/diabetes, oxidative stress, inflammation, hypertension, blood-brain barrier dysfunctions, and brain edema. These responses, combined with the altered sleep macro- and microarchitecture, may lead to small-vessel disease, microinfarcts, strokes, reduced neurogenesis, reduced synaptic plasticity, decreased cognitive functioning, changes in brain white and gray matter, changes in cerebral networks, and abnormal levels of Alzheimer's disease biomarkers, which can all be involved in abnormal cognitive decline and dementia. Mechanisms in yellow boxes/dashed rectangle may all interact to create a vicious cycle; they also have the potential to alter sleep architecture and play a role in the systemic and brain responses to hypoxemia. 
chronic sleep deprivation doubled $A \beta$ levels in the brain (28). Moreover, sleep is implicated in the clearance of toxic proteins and metabolic waste accumulated during wakefulness through interstitial space expansion during sleep, which promotes fluid exchange with CSF (1). Regarding this latter mechanistic hypothesis, three potential mechanisms could be involved: 1) intrathoracic pressure swings from respiratory efforts against a closed airway that would impede the glymphatic flow of metabolites from interstitial fluid to the CSF (29), 2) a reduction in the clearance of subarachnoid CSF directly into dural lymphatic channels due to increased venous pressure that is typically elevated in OSA, and 3) cerebral edema secondary to intermittent hypoxia that reduces interstitial space expansion (30). Finally, several animal models showed that hypoxia could play an important role in the $A \beta$ cascade via HIF-1 $\alpha$ (hypoxiainducible factor-1 $\alpha$ ), which increases the activity of various secretases (including BACE1), leading to an elevated production of $A \beta$ peptides (31). In addition to increased $A \beta$ generation, hypoxia affects peptidases that degrade $\mathrm{A} \beta$ peptides, thus reducing $\mathrm{A} \beta$ clearance. Finally, hypoxia reduces the activity of the neuroprotective $\alpha$-secretase, furthering the $A \beta$ cascade.

Responses to upper airway obstruction can also affect brain health with age. In fact, apneas and hypopneas provoke adaptive (e.g., ischemic preconditioning) but also maladaptive and potentially harmful responses (e.g., oxidative stress, inflammation, hypertension, dysautonomia, impaired glucose tolerance, and blood-brain barrier dysfunction) that may damage cerebral cells and organelles, and make neurons more susceptible to cellular death (32). Not surprisingly, studies have shown that severe OSA increases the risk of cerebral small-vessel disease (33) and stroke (34). In a postmortem study of 167 older adults, hypoxemia measured on prior polysomnographic recordings was associated with more brain microinfarcts at autopsy (35). When only hypoxemia during REM sleep was considered in that study, a significant association was also found for gliosis and neuronal loss in the locus coeruleus. The locus coeruleus is a brainstem region responsible for norepinephrine supply that shows early neurofibrillary tangle formation due to aggregation of hyperphosphorylated tau protein in $\mathrm{AD}$ (36). Interestingly, this region is involved in the control of the sleep-wake cycle. Hypoxemia possibly affects regions involved in regulation of the sleep-wake cycle (e.g., locus coeruleus and dorsal raphe nucleus), creating subsequent sleep disruption and then contributing to more $A \beta$ accumulation (see Reference 37 for a more detailed discussion); this hypothesis needs further investigation.

\section{How Brain Structure and Function Change in Older Adults with OSA}

Most neuroimaging studies on OSA have been performed in young and middle-aged adults. Whether these findings can be generalized to an aged brain is unclear, as neuroimaging studies with older adults have only just emerged. Neuroimaging techniques allow indirect and large-scale measurements of neuroanatomical structures and their functioning. Given the complexity of changes that can occur in response to OSA (e.g., cellular death, edema, increase in brain water content, neuroinflammation, changes in cerebral perfusion, and increase in $\mathrm{A} \beta$ deposition), heterogeneous results can be obtained depending on the participants' age, severity of intermittent hypoxia and sleep fragmentation, clinical stages of dementia, and so on. OSA may also lead to nonlinear changes in brain structure and function due to phasic adaptive and maladaptive responses. As an example, studies in young and middle-aged adults usually show gray matter atrophy in patients with OSA as compared with control subjects, and the parahippocampal and frontotemporal cortex are the brain regions most consistently affected (38). However, in a study of adults aged 55-76 years, OSA severity was associated with gray matter hypertrophy and higher cortical thickness in frontal, parietal, and cingulate regions, as well as in the amygdala (39). This pattern of gray matter hypertrophy and thickening in middle-aged and older patients with OSA may be due to local increases in brain water content secondary to hypoxia, inflammation, and/or with $A \beta$ deposition. In accordance with this hypothesis, recent studies showed that more severe OSA is associated with increased rates of $A \beta$ deposition, using Pittsburgh compound B-positron emission tomographic imaging in older adults $(25,40)$. On the other hand, whether hypertrophy represents acute adaptive mechanisms such as edema or reactive gliosis in milder OSA forms is an interesting question that would need to be addressed.

Cerebral white matter is vulnerable to hypoxia as well, and results from the literature also underline the complex changes in brain structure associated with OSA. Rather than reporting the typical patterns of diffusion associated with white matter loss, most studies using diffusion tensor imaging in young and middle-aged adults have found reduced diffusivities along white matter tracks in OSA (41-43). Reduced diffusivity suggests that an ongoing brain response to OSA, such as swelling or increased brain water content, prevents water movement. This pattern of reduced diffusivities was previously observed in acute and/or preclinical stages of familial AD and stroke $(44,45)$. Whether these changes evolve into neuronal death still needs to be verified with longitudinal studies.

Regarding cerebral functioning, a systematic review that included six studies of young and middle-aged adults reported reduced resting-state functional connectivity within and between several regions including the hippocampus, the posterior cingulate, the medial prefrontal cortex, the medial temporal lobe, the basal ganglia, the insula, and the cerebellum (46). In parallel, a functional neuroimaging study in adults aged 55 years and older measured regional cerebral blood flow using single-photon emission computed tomography and showed that participants with severe OSA had hypoperfusion in sensorimotor areas and the parietal lobes (47). Moreover, hypoperfusions in the parietal, temporal, and frontal lobes were associated with higher levels of respiratory disturbances, daytime sleepiness, and obesity. Hence, functional neuroimaging is sensitive to changes associated with OSA. However, studies with elderly participants are needed to verify whether anomalies observed in younger subjects are applicable to the older population and are predictive of a cognitive decline. In that context, longitudinal neuroimaging 
studies would allow clarification of the evolution of brain functional changes in elderly individuals with OSA.

\section{How Treating OSA Impacts the Aging Brain}

OSA treatment, such as CPAP, is effective for reducing hypopneic and apneic events. However, patients generally suffer from OSA for several years before being diagnosed and treated. Whether CPAP treatment can slow down, stop, or reverse neurodegenerative processes potentially accentuated by OSA is a crucial question, particularly for patients who start their treatment after the age of 65 years. Unfortunately, most published studies investigating the effect of CPAP on brain health were performed among young and middle-aged patients. However, in a randomized study of 33 patients with OSA aged $71.3 \pm 5.5$ years, 3 months of CPAP improved short-term memory, working memory, selective attention, and executive functions as well as functional connectivity in the right middle frontal gyrus (48). More recently, preliminary evidence in a nondemented cohort of elderly participants, involved in a study from the Alzheimer's Disease Neuroimaging Initiative, showed that CPAP treatment delayed the age of MCI onset by approximately 10 years (72 vs. $82 \mathrm{yr}$ old), whereas age at MCI onset in participants reporting treated OSA was similar to the nonOSA group (10). A recent case study of a patient with OSA and subjective cognitive impairment showed that 1 year of CPAP treatment normalized the CSF $\mathrm{A} \beta 42$ and $\mathrm{t}-$ tau/A $\beta 42$ ratio levels as well as the cognitive complaints (49), suggesting that OSA might be a reversible risk factor for dementia. However, a 12-month randomized trial showed no effect of CPAP on cognitive function in adults aged 65 and older, despite improvement in sleepiness (50). This absence of changes in cognitive function could be attributed to a ceiling effect, as the participants had normal cognitive performance at baseline. However, negative results from this study should be interpreted with caution due to the overall low compliance of this cohort. More studies are urgently needed to confirm these preliminary findings and expand our knowledge regarding the effect of OSA treatment on neurodegeneration in the elderly.

Another important issue relates to the effect of OSA in patients already presenting a neurodegenerative disease. According to a recent meta-analysis, patients with $\mathrm{AD}$ have a $50 \%$ chance of experiencing OSA after their dementia diagnosis (51). The authors hypothesized that this high rate of OSA in $\mathrm{AD}$ could be due to the possible role of OSA in dementia pathogenesis. In a series of pioneer studies by Ancoli-Israel and colleagues, reduced daytime sleepiness and cognitive deficits, as well as improvement in sleep quality, were observed after treatment with CPAP in patients with AD (52-54).

Slower cognitive decline on the Mini Mental State Examination was also reported in another study of mild to moderate $\mathrm{AD}$ in patients with severe OSA treated with CPAP compared with nontreated patients (55). These results support the hypothesis that OSA aggravates cognitive dysfunction when neurodegenerative processes are already present and that CPAP can have a positive impact on cognitive functioning in the demented population.

This aggravation effect of OSA on cognition is not limited to patients with $\mathrm{AD}$ and is also common in patients with other neurodegenerative conditions. For instance, OSA in nondemented patients with Parkinson's disease (PD) increases sleepiness and reduces global cognition (56). Moreover, treatment of OSA was associated with stabilization of motor function (57) and improvement in sleep quality, sleepiness (58), and cognitive function, particularly in those with reduced function at baseline (59), although a shorter trial found no change in cognition (60). Another important question is whether OSA has an impact on the progression of motor dysfunction and the overall neurodegenerative process of $\mathrm{PD}$. A recent study suggests that OSA increases the risk of developing PD in women (61). Hence, OSA might be a risk factor for cognitive decline in neurodegenerative disorders, with the predominant pathology and clinical manifestations depending on predisposing factors. CPAP therapy is challenging in patients with a neurodegenerative disease or dementia due to anxiety, nocturia, insomnia, and cognitive and motor impairment affecting the ability to wear the mask, but studies have shown that it is feasible $(52-54,56)$. In one study, the presence of depressive symptoms in patients with OSA and mild to moderate $\mathrm{AD}$ was associated with worse CPAP adherence (62). There is, however, a lack of studies on long-term adherence to CPAP in older adults with dementia. Moreover, it is not known whether strategies that improve compliance with CPAP in nondemented adults (e.g., feedback of compliance data) (63) are also efficient in patients with $\mathrm{AD}$. The involvement of relatives is probably a major factor in short- and long-term CPAP adherence in this clinical population.

\section{Risk Factors and Prevention of Cognitive Decline in the Context of OSA}

Few studies have investigated whether some factors moderate, that is, reinforce or weaken, the association between OSA severity and cognitive impairment. It is possible that individual characteristics or comorbidities can make some older adults with OSA more or less at risk of developing dementia. For example, a 5-year longitudinal cohort study of 7,547 men showed that self-reported OSA was associated with risk of dementia only in APOE4 noncarriers (64). However, the reverse result was found in three crosssectional studies, where the association between OSA and impaired cognition was stronger in APOE4 carriers than in noncarriers (65-67).

\section{Future Directions}

Research on the long-term neurocognitive consequences of OSA is just emerging, but recent studies have transformed this field by moving the focus from middle-aged to older adults. Still, few longitudinal studies with objective monitoring for OSA have been published. This type of study design is necessary to reveal how cognitive functioning in the elderly evolves in the context of OSA.

- One of the first lines of research could be to identify vulnerable patients with OSA who could benefit the most from treatment. In addition, whether OSA in patients with mild to moderate disease, who are asymptomatic or present mild daytime symptoms, could lead to dementia in the long term is not clear. We need to characterize genetic, sleep, and/or respiratory characteristics that put patients at greater risk of dementia. 
For clinical purposes, we have to validate screening tests and biomarkers (e.g., genetics, blood biomarkers, and neuroimaging) that could identify vulnerable patients.

- There is a need to study how factors that are already known to affect the clinical expression of dementia, for example, age, sex, hypertension, hypercholesterolemia, diabetes, smoking, depression, metabolic syndrome, and obesity (68), influence the evolution of cognitive decline in adults with OSA. Considering that OSA is frequently caused by obesity and is a risk factor for hypertension, diabetes, and depression (69), studying their additive or interacting roles could help identify those adults more vulnerable to the neurocognitive effects of OSA.

- We also need to understand how lifestyle (e.g., high education or cognitive reserve, healthy diet, physical exercise, social activities) could prevent the deleterious effects of OSA on brain health. For example, exercise training has been described as having positive effects on OSA severity in sedentary overweight/obese young and middleaged adults (70). Moreover, we need to verify whether physical activity can reduce $A \beta$ deposition, as previously described in nonapneic participants (71).

- Another line of research is to clarify the mechanistic processes that link OSA to dementia, to identify novel targets for intervention. Preliminary evidence suggests that cognitive decline in OSA may share similar mechanisms with those already described in $\mathrm{AD}$ (i.e., aggregation of $A \beta$ and tau in the brain) or vascular dementia. These results should be confirmed in longitudinal studies. In the same manner, whether brain structure and function anomalies in nondemented older adults with OSA evolve into dementia is unknown. Testing mechanistic hypotheses explaining the impact of OSA on human cerebral physiology and function warrants the use of the most advanced neuroimaging methodologies.

- Another important aspect is to determine the long-term effects of OSA treatment on neurocognitive health. Several variables need to be considered, including the age at OSA diagnosis and age when treatment was started. We need to determine thresholds for minimum
CPAP use and duration to be effective on cognitive function. Whether OSA treatment can stop or reverse the cognitive decline of older adults presenting with MCI needs to be investigated.

- It will be important to evaluate the therapeutic and economic costs and benefits of CPAP in older people, particularly in those with mild or moderate OSA, and include a particular consideration of cognitive decline in the cost-effectiveness analysis.

- The long-term neurocognitive consequences of untreated OSA are generally not considered in treatment decision making. It is noteworthy that we now have sufficient evidence supporting the role of sleep quality and duration in neurocognitive health to make sustained efforts to translate this knowledge. Although this latter point is not a research objective, it should be considered a priority to transform clinical practice and public health policies.

Author disclosures are available with the text of this article at www.atsjournals.org.

\section{References}

1. Xie L, Kang H, Xu Q, Chen MJ, Liao Y, Thiyagarajan M, et al. Sleep drives metabolite clearance from the adult brain. Science 2013; 342:373-377.

2. Musiek ES, Holtzman DM. Mechanisms linking circadian clocks, sleep, and neurodegeneration. Science 2016;354:1004-1008.

3. Punjabi NM. The epidemiology of adult obstructive sleep apnea. Proc Am Thorac Soc 2008;5:136-143.

4. Braley TJ, Dunietz GL, Chervin RD, Lisabeth LD, Skolarus LE, Burke JF. Recognition and diagnosis of obstructive sleep apnea in older Americans. J Am Geriatr Soc 2018;66:1296-1302.

5. Wolkove N, Baltzan M, Kamel H, Dabrusin R, Palayew M. Long-term compliance with continuous positive airway pressure in patients with obstructive sleep apnea. Can Respir J 2008;15:365-369.

6. Doff $\mathrm{MH}$, Hoekema A, Wijkstra $\mathrm{PJ}$, van der Hoeven JH, Huddleston Slater JJ, de Bont LG, et al. Oral appliance versus continuous positive airway pressure in obstructive sleep apnea syndrome: a 2-year follow-up. Sleep 2013;36:1289-1296.

7. Bucks RS, Olaithe M, Eastwood P. Neurocognitive function in obstructive sleep apnoea: a meta-review. Respirology 2013;18:61-70.

8. Leng Y, McEvoy CT, Allen IE, Yaffe K. Association of sleep-disordered breathing with cognitive function and risk of cognitive impairment: a systematic review and meta-analysis. JAMA Neurol 2017;74:12371245.

9. Yaffe K, Laffan AM, Harrison SL, Redline S, Spira AP, Ensrud KE, et al. Sleep-disordered breathing, hypoxia, and risk of mild cognitive impairment and dementia in older women. JAMA 2011;306:613-619.

10. Osorio RS, Gumb T, Pirraglia E, Varga AW, Lu SE, Lim J, et al.; Alzheimer's Disease Neuroimaging Initiative. Sleep-disordered breathing advances cognitive decline in the elderly. Neurology 2015; 84:1964-1971.
11. Martin MS, Sforza E, Roche F, Barthélémy JC, Thomas-Anterion C; PROOF Study Group. Sleep breathing disorders and cognitive function in the elderly: an 8-year follow-up study: the PROOFSYNAPSE cohort. Sleep 2015;38:179-187.

12. Cross N, Lampit A, Pye J, Grunstein RR, Marshall N, Naismith SL. Is obstructive sleep apnoea related to neuropsychological function in healthy older adults? A systematic review and meta-analysis. Neuropsychol Rev 2017;27:389-402.

13. Rosenzweig I, Glasser M, Polsek D, Leschziner GD, Williams SC, Morrell MJ. Sleep apnoea and the brain: a complex relationship. Lancet Respir Med 2015;3:404-414.

14. Meerlo P, Mistlberger RE, Jacobs BL, Heller HC, McGinty D. New neurons in the adult brain: the role of sleep and consequences of sleep loss. Sleep Med Rev 2009;13:187-194.

15. Cirelli C. Sleep and synaptic changes. Curr Opin Neurobiol 2013;23: 841-846.

16. Van Dongen HP, Dinges DF. Sleep, circadian rhythms, and psychomotor vigilance. Clin Sports Med 2005;24:237-249, vii-viii.

17. Born J, Wilhelm I. System consolidation of memory during sleep. Psychol Res 2012;76:192-203.

18. De Gennaro L, Gorgoni M, Reda F, Lauri G, Truglia I, Cordone S, et al. The fall of sleep K-complex in Alzheimer disease. Sci Rep 2017;7:39688.

19. Heinzer R, Gaudreau H, Décary A, Sforza E, Petit D, Morisson F, et al. Slow-wave activity in sleep apnea patients before and after continuous positive airway pressure treatment: contribution to daytime sleepiness. Chest 2001;119:1807-1813.

20. Carvalho DZ, Gerhardt GJ, Dellagustin G, de Santa-Helena EL, Lemke N Segal AZ, et al. Loss of sleep spindle frequency deceleration in obstructive sleep apnea. Clin Neurophysiol 2014;125:306-312.

21. Nguyen CD, Wellman A, Jordan AS, Eckert DJ. Mild airflow limitation during N2 sleep increases K-complex frequency and slows electroencephalographic activity. Sleep 2016;39:541-550. 
22. Stern Y. What is cognitive reserve? Theory and research application of the reserve concept. J Int Neuropsychol Soc 2002;8:448-460.

23. Polanco JC, Li C, Bodea LG, Martinez-Marmol R, Meunier FA, Götz J. Amyloid- $\beta$ and tau complexity: towards improved biomarkers and targeted therapies. Nat Rev Neurol 2018;14:22-39.

24. Liguori C, Mercuri NB, Izzi F, Romigi A, Cordella A, Sancesario G, et al. Obstructive sleep apnea is associated with early but possibly modifiable Alzheimer's disease biomarkers changes. Sleep 2017;40(5). DOI: 10.1093/sleep/zsx011.

25. Sharma RA, Varga AW, Bubu OM, Pirraglia E, Kam K, Parekh A, et al. Obstructive sleep apnea severity affects amyloid burden in cognitively normal elderly: a longitudinal study. Am J Respir Crit Care Med 2018;197:933-943.

26. Ju YE, Finn MB, Sutphen CL, Herries EM, Jerome GM, Ladenson JH, et al. Obstructive sleep apnea decreases central nervous systemderived proteins in the cerebrospinal fluid. Ann Neurol 2016;80:154159.

27. Brown BM, Rainey-Smith SR, Bucks RS, Weinborn M, Martins RN. Exploring the bi-directional relationship between sleep and $\beta$-amyloid. Curr Opin Psychiatry 2016;29:397-401.

28. Kang JE, Lim MM, Bateman RJ, Lee JJ, Smyth LP, Cirrito JR, et al. Amyloid- $\beta$ dynamics are regulated by orexin and the sleep-wake cycle. Science 2009;326:1005-1007.

29. Dreha-Kulaczewski S, Joseph AA, Merboldt KD, Ludwig HC, Gärtner J, Frahm J. Identification of the upward movement of human CSF in vivo and its relation to the brain venous system. $J$ Neurosci 2017; 37:2395-2402.

30. Baronio D, Martinez D, Fiori CZ, Bambini-Junior V, Forgiarini LF, Pase da Rosa D, et al. Altered aquaporins in the brains of mice submitted to intermittent hypoxia model of sleep apnea. Respir Physiol Neurobiol 2013;185:217-221.

31. Salminen A, Kauppinen A, Kaarniranta K. Hypoxia/ischemia activate processing of amyloid precursor protein: impact of vascular dysfunction in the pathogenesis of Alzheimer's disease. $J$ Neurochem 2017;140:536-549.

32. Rosenzweig I, Williams SC, Morrell MJ. The impact of sleep and hypoxia on the brain: potential mechanisms for the effects of obstructive sleep apnea. Curr Opin Pulm Med 2014;20:565-571.

33. Kim H, Yun CH, Thomas RJ, Lee SH, Seo HS, Cho ER, et al. Obstructive sleep apnea as a risk factor for cerebral white matter change in a middle-aged and older general population. Sleep 2013;36: 709B-715B.

34. Xie C, Zhu R, Tian Y, Wang K. Association of obstructive sleep apnoea with the risk of vascular outcomes and all-cause mortality: a metaanalysis. BMJ Open 2017;7:e013983.

35. Gelber RP, Redline S, Ross GW, Petrovitch H, Sonnen JA, Zarow C, et al. Associations of brain lesions at autopsy with polysomnography features before death. Neurology 2015;84:296-303.

36. Braak H, Del Tredici K. The preclinical phase of the pathological process underlying sporadic Alzheimer's disease. Brain 2015;138: 2814-2833.

37. Šimić G, Babić Leko M, Wray S, Harrington CR, Delalle I, JovanovMilošević N, et al. Monoaminergic neuropathology in Alzheimer's disease. Prog Neurobiol 2017;151:101-138.

38. Weng HH, Tsai YH, Chen CF, Lin YC, Yang CT, Tsai YH, et al. Mapping gray matter reductions in obstructive sleep apnea: an activation likelihood estimation meta-analysis. Sleep 2014;37:167175.

39. Baril AA, Gagnon K, Brayet P, Montplaisir J, De Beaumont L, Carrier J, et al. Gray matter hypertrophy and thickening with obstructive sleep apnea in middle-aged and older adults. Am J Respir Crit Care Med 2017;195:1509-1518.

40. Yun CH, Lee HY, Lee SK, Kim H, Seo HS, Bang SA, et al. Amyloid burden in obstructive sleep apnea. J Alzheimers Dis 2017;59:21-29.

41. Castronovo V, Scifo P, Castellano A, Aloia MS, ladanza A, Marelli S, et al. White matter integrity in obstructive sleep apnea before and after treatment. Sleep 2014;37:1465-1475.

42. Kumar R, Chavez AS, Macey PM, Woo MA, Yan-Go FL, Harper RM. Altered global and regional brain mean diffusivity in patients with obstructive sleep apnea. J Neurosci Res 2012;90:2043-2052.
43. Kumar R, Pham TT, Macey PM, Woo MA, Yan-Go FL, Harper RM. Abnormal myelin and axonal integrity in recently diagnosed patients with obstructive sleep apnea. Sleep 2014;37:723-732.

44. Pitkonen M, Abo-Ramadan U, Marinkovic I, Pedrono E, Hasan KM, Strbian D, et al. Long-term evolution of diffusion tensor indices after temporary experimental ischemic stroke in rats. Brain Res 2012; 1445:103-110.

45. Ryan NS, Keihaninejad S, Shakespeare TJ, Lehmann M, Crutch SJ, Malone IB, et al. Magnetic resonance imaging evidence for presymptomatic change in thalamus and caudate in familial Alzheimer's disease. Brain 2013;136:1399-1414.

46. Khazaie H, Veronese M, Noori K, Emamian F, Zarei M, Ashkan K, et al. Functional reorganization in obstructive sleep apnoea and insomnia: a systematic review of the resting-state fMRI. Neurosci Biobehav Rev 2017;77:219-231.

47. Baril AA, Gagnon K, Arbour C, Soucy JP, Montplaisir J, Gagnon JF, et al. Regional cerebral blood flow during wakeful rest in older subjects with mild to severe obstructive sleep apnea. Sleep 2015;38: 1439-1449.

48. Dalmases M, Solé-Padullés C, Torres M, Embid C, Nuñez MD, Martínez-Garcia MA, et al. Effect of CPAP on cognition, brain function, and structure among elderly patients with OSA: a randomized pilot study. Chest 2015;148:1214-1223.

49. Liguori C, Chiaravalloti A, Izzi F, Nuccetelli M, Bernardini S, Schillaci O, et al. Sleep apnoeas may represent a reversible risk factor for amyloid- $\beta$ pathology. Brain 2017;140:e75.

50. McMillan A, Bratton DJ, Faria R, Laskawiec-Szkonter M, Griffin S, Davies RJ, et al.; PREDICT Investigators. Continuous Positive Airway Pressure in Older People with Obstructive Sleep Apnoea Syndrome (PREDICT): a 12-month, multicentre, randomised trial. Lancet Respir Med 2014;2:804-812.

51. Emamian F, Khazaie H, Tahmasian M, Leschziner GD, Morrell MJ, Hsiung GY, et al. The association between obstructive sleep apnea and Alzheimer's disease: a meta-analysis perspective. Front Aging Neurosci 2016;8:78.

52. Ancoli-Israel S, Palmer BW, Cooke JR, Corey-Bloom J, Fiorentino L, Natarajan L, et al. Cognitive effects of treating obstructive sleep apnea in Alzheimer's disease: a randomized controlled study. J Am Geriatr Soc 2008;56:2076-2081.

53. Chong MS, Ayalon L, Marler M, Loredo JS, Corey-Bloom J, Palmer BW, et al. Continuous positive airway pressure reduces subjective daytime sleepiness in patients with mild to moderate Alzheimer's disease with sleep disordered breathing. J Am Geriatr Soc 2006;54: 777-781.

54. Cooke JR, Ancoli-Israel S, Liu L, Loredo JS, Natarajan L, Palmer BS, et al. Continuous positive airway pressure deepens sleep in patients with Alzheimer's disease and obstructive sleep apnea. Sleep Med 2009;10:1101-1106.

55. Troussière AC, Charley CM, Salleron J, Richard F, Delbeuck $X$ Derambure $P$, et al. Treatment of sleep apnoea syndrome decreases cognitive decline in patients with Alzheimer's disease. J Neurol Neurosurg Psychiatry 2014;85:1405-1408.

56. Mery VP, Gros P, Lafontaine AL, Robinson A, Benedetti A, Kimoff RJ, et al. Reduced cognitive function in patients with Parkinson disease and obstructive sleep apnea. Neurology 2017;88: 1120-1128.

57. Meng LL, Mery V, Benedetti A, Lafontaine AL, Robinson A, Gros P, et al. Association between obstructive sleep apnea and motor symptoms in Parkinson's disease patients [abstract]. Am J Respir Crit Care Med 2018;197:A2947.

58. Neikrug AB, Liu L, Avanzino JA, Maglione JE, Natarajan L, Bradley L, et al. Continuous positive airway pressure improves sleep and daytime sleepiness in patients with Parkinson disease and sleep apnea. Sleep 2014;37:177-185.

59. Kaminska M, Mery VP, Lafontaine AL, Robinson A, Benedetti A, Gros P, et al. Change in cognition and other non-motor symptoms with obstructive sleep apnea treatment in Parkinson disease. J Clin Sleep Med 2018;14:819-828.

60. Harmell AL, Neikrug AB, Palmer BW, Avanzino JA, Liu L, Maglione JE, et al. Obstructive sleep apnea and cognition in Parkinson's disease. Sleep Med 2016;21:28-34. 
61. Sheu JJ, Lee HC, Lin HC, Kao LT, Chung SDA. A 5-year follow-up study on the relationship between obstructive sleep apnea and Parkinson disease. J Clin Sleep Med 2015;11:1403-1408.

62. Ayalon L, Ancoli-Israel S, Stepnowsky C, Marler M, Palmer BW, Liu L, et al. Adherence to continuous positive airway pressure treatment in patients with Alzheimer's disease and obstructive sleep apnea. Am J Geriatr Psychiatry 2006;14:176-180.

63. Kuna ST, Shuttleworth D, Chi L, Schutte-Rodin S, Friedman E, Guo H, et al. Web-based access to positive airway pressure usage with or without an initial financial incentive improves treatment use in patients with obstructive sleep apnea. Sleep 2015;38: 1229-1236.

64. Ding X, Kryscio RJ, Turner J, Jicha GA, Cooper G, Caban-Holt A, et al. Self-reported sleep apnea and dementia risk: findings from the Prevention of Alzheimer's Disease with Vitamin E and Selenium Trial. J Am Geriatr Soc 2016;64:2472-2478.

65. Johnson DA, Lane J, Wang R, Reid M, Djonlagic I, Fitzpatrick AL, et al.; Multi-Ethnic Study of Atherosclerosis. Greater cognitive deficits with sleep-disordered breathing among individuals with genetic susceptibility to Alzheimer disease. Ann Am Thorac Soc 2017;14: $1697-1705$
66. Nikodemova M, Finn L, Mignot E, Salzieder N, Peppard PE. Association of sleep disordered breathing and cognitive deficit in APOE $\varepsilon 4$ carriers. Sleep 2013;36:873-880.

67. Spira AP, Blackwell T, Stone KL, Redline S, Cauley JA, Ancoli-Israel S, et al. Sleep-disordered breathing and cognition in older women. $J$ Am Geriatr Soc 2008;56:45-50.

68. Baumgart M, Snyder HM, Carrillo MC, Fazio S, Kim H, Johns H. Summary of the evidence on modifiable risk factors for cognitive decline and dementia: a population-based perspective. Alzheimers Dement 2015;11:718-726.

69. Jennum P, Riha RL. Epidemiology of sleep apnoea/hypopnoea syndrome and sleep-disordered breathing. Eur Respir J 2009;33: 907-914.

70. Kline CE, Crowley EP, Ewing GB, Burch JB, Blair SN, Durstine JL, et al. The effect of exercise training on obstructive sleep apnea and sleep quality: a randomized controlled trial. Sleep 2011;34:16311640.

71. Merrill DA, Siddarth P, Raji CA, Emerson ND, Rueda F, Ercoli LM, et al. Modifiable risk factors and brain positron emission tomography measures of amyloid and tau in nondemented adults with memory complaints. Am J Geriatr Psychiatry 2016;24:729-737. 